\title{
AOR
}

Selected Papers of \#AoIR2021:

The 22nd Annual Conference of the

Association of Internet Researchers

Virtual Event / 13-16 Oct 2021

\section{NARRATIVES IN AMERICA: THE CONNECTION BETWEEN AFFECTIVE POLARIZATION AND VICTIMHOOD IN THE 2020 US ELECTION}

\author{
Hoda Gharib: \\ University of Toronto \\ Professor Megan Boler \\ University of Toronto
}

\section{Introduction:}

Recent literature on polarization indicates that societal divisions are not only based in ideological and policy differences, but can also occur at the level of emotion and identity. Affective polarization has been used to describe the dislike and distrust that members of an ingroup have for an outgroup and studies indicate that American citizens are reporting increasing levels of affective polarization and behavioural distancing from members of other political groups (lyengar et al., 2019). The 2020 US election and its aftermath coupled with the Black Lives Matter protests during summer of 2020 have highlighted the negative emotions and beliefs that citizens feel towards outgroup members. This study explores the narratives held by individuals on the political right and left about self and other. What are the beliefs that they hold about the self/other and which emotions do they feel? What stories do these beliefs and emotions tell about group identity and belonging in America and about each group's relationship to the state and its institutions?

We bring Horwitz's 2018 article on the politics of victimhood into conversation with affective polarization, building on these to contribute original insights regarding how narratives of victimhood and blame may exacerbate affective polarization. Horwitz (2018) argues that victimhood "has become among the most important identity positions in American politics" (pg. 553). Despite the stigma around victimhood as a position of weakness, inferiority, and powerlessness, to be a victim is to hold power, particularly in relation to morality. Victims have a claim over justice because it is they who have been wronged and they who have the injury that needs to be recognised and rectified by powerful institutions (Horwitz, 2018). Thus, victimhood imparts on the victim a sense of moral superiority and can become a site of contestation in society. Our study seeks to understand how claims over victimhood manifest in contexts of heightened partisan and racial tensions. We draw further on the concept of "deep stories", theorized by 
sociologist Arlie Hochschild (2016) to describe the affectively-charged narratives underlying all political ideologies (such as the American Dream). A deep story "describes pain, blame, and points to a rescue narrative; it provides an emotional accounting system, establishing an accounting of who deserves sympathy, distrust, shame" (pg. 135). The concept of "deep stories" provides a framework for analyzing polarization and how narratives about race and national identities are linked with strong emotions.

Through extensive 4-month ethnography and grounded theoretical coding and discourse analysis of 2500 social media posts and comment sections, we address debates relating to the nature of cross-partisan dialogue and affective polarization on social media. Citing the mixed results on the potential of social media to serve as a productive public sphere, Bouvier \& Rosenbaum (2020) call for deeper analysis of this question through research in a variety of political contexts. Our study contributes to this ongoing debate by exploring these questions in a highly polarized context and during divisive and tense historical moments in the US.

\section{Methodology:}

This mixed-methods, three-year project (funded by the Canadian Social Sciences and Humanities Research Council) explores how emotions are expressed in relation to narratives of racial and national belonging within election-related social media.

Engaging grounded theory (Charmaz, 2006), the cross-platform study explores Twitter, Facebook, and Gab in the context of the 2019 Canadian and 2020 U.S. elections. Over the past two years, the PI and a seven-person team developed an innovative approach of affective discourse analysis through collaborative and iterative weekly meetings. The four-month digital ethnography, conducted in the lead up to and aftermath of each federal election, tracked developing stories and debates within social media conversations across the political spectrum. Observations were documented in extensive field notes and discussed in weekly meetings. We coded a sample of 2500 posts discussing the January 6th Capitol Riots, election fraud, and Black Lives Matter protests using the qualitative data research software Atlas.ti. Threads were selected according to the following criteria: initiated by an influencer; reflecting cross-partisan dialogue; explicit address of race; and having more than 300 comments/responses. Contributing an innovative approach to the analysis of affect and emotion within social media, our affective discourse analysis was developed through an intensive iterative process over two years, drawing from critical discourse analysis (Wodak \& Meyer, 2015), rhetorical analysis (Leach, 2000), and "narrative emotions" analysis (Kleres, 2011). We engaged grounded theory to develop and refine a codebook suitable for the complex task of coding emotional expression, including: rhetorical and linguistic features; topics to which emotions were directed; and beliefs about ingroups and outgroups.

\section{Results:}


One of the most prominent findings to emerge from our data relating to emotions was frequent distrust of the other. Individuals tended to demonstrate distrust in others who displayed opposing views to their own as well as to others' political and media institutions. This distrust was manifested in several ways. For example, when individuals provided idiosyncratic or "authoritative" evidence (e.g., news articles) to support their argument, they were met with dismissal or accusations of bias or lying. On Gab, we frequently saw distrust in the form of right-leaning individuals calling leftleaning individuals "trolls" and accusing them of being "paid" to repeat a predetermined "script". Finally, left-leaning individuals showed distrust in right-leaning individuals' claims that the January 6 Capitol events were a result of "passion and love" for America; as one user exclaims, "Passionate about America? You sound like a damn fool".

Our findings on beliefs confirm previous literature by showing that members of the ingroup tend to believe that they are critical thinkers, innocent, and oppressed, while members of the outgroup are brainwashed, hypocrites, and unpatriotic. Affective polarization literature, largely quantitative, understand polarization almost solely in terms of partisan identity, and conceptualizes emotion in terms of a "positive/negative" binary. Our research provides greater nuance and complexity, revealing the extensive feelings of bitterness and resentment of the other in U.S. politics. These feelings are linked to the ingroup's narrative of victimhood and blame: the ingroup feels victimised and hurt by the outgroup which not only refuses to recognize this pain but in fact is the cause. Significantly, our analysis supports sociologist Arlie Hochschild's theorization of "deep stories." This was common across both right and left-leaning threads; those who disagreed with one's interpretation of victimhood and blame were treated as outsiders, dismissed, and mocked. Moreover, pain was exacerbated by perceptions of double standards that privileged the outgroup and discriminated against the ingroup. Discourses of double standards were particularly common among left-leaning individuals, who felt that the police response to the storming of the capitol was disproportionately lenient in comparison to their response to Black Lives Matter protests and that this leniency was a product of racism and underlying partisan loyalties.

\section{Conclusion:}

Through innovative and nuanced coding of emotions, beliefs, and narratives of self/other on social media, our study deepens understandings of the nature and manifestation of affective polarization in the U.S. Our findings shed new light on the interconnectedness of extreme societal divisions and ingroup victimhood, outgroup blame and feelings of bitterness and resentment. We contribute insights into dynamics of distrust, and particularly the predominant accusations of hypocrisy and doublestandards from across the political spectrum. In addition to addressing gaps in scholarly understanding of the nature of polarization within social media and cross-partisan dialogue in our increasingly polarized landscape, our research contributes an innovative approach to coding emotional expressions on social media.

\section{References:}


Bouvier, G., \& Rosenbaum, J. E. (Eds.). (2020). Twitter, the public sphere, and the chaos of online deliberation. Palgrave Macmillan.

Charmaz, K. (2014). Constructing grounded theory. Sage.

Horwitz, R. B. (2018). Politics as victimhood, victimhood as politics. Journal of Policy History, 30(3), 552-574.

lyengar, S., Lelkes, Y., Levendusky, M., Malhotra, N., \& Westwood, S. J. (2019). The origins and consequences of affective polarization in the United States. Annual Review of Political Science, 22, 129-146.

Kleres, J. (2011). Emotions and narrative analysis: A methodological approach. Journal for the theory of social behaviour, 41(2), 182-202.

Leach, J. (2000). Rhetorical analysis. In Bauer, M.W. \& Gaskell, G. (Eds), Qualitative researching with text, image and sound, 207-226. Sage.

Wodak, R., \& Meyer, M. (Eds.). (2015). Methods of critical discourse studies. Sage. 